\title{
Antibiotic prophylaxis for prevention against Lyme disease following tick bite: an updated systematic review and meta-analysis
}

\author{
Guozhong Zhou', Xin Xu', Yu Zhang ', Peng Yue', Shiqi Luo', Yuxin Fan'1, Jingjing Chen' ', Meixiao Liu', \\ Yan Dong ${ }^{1}$, Bingxue Li ${ }^{1}$, Jing Kong ${ }^{1}$, Shiyuan Wen', Aihua Liu ${ }^{1,2^{*}}$ and Fukai Bao ${ }^{1,2^{*}}$
}

\begin{abstract}
Background: In areas where Lyme disease is endemic, bites from ticks are common, but no vaccine is currently available against Lyme disease for humans. Therefore, the feasibility of using antibiotic prophylaxis to prevent Lyme disease after a tick bite is worth further exploration. Previous meta-analyses lack sufficient power to demonstrate the efficacy of about antibiotic prophylaxis for the prevention of Lyme disease following a tick bite. In this study, we explored more precise evidence and attempted to identify and update optimum treatment strategies.

Methods: We searched PubMed, Embase, and the Cochrane Library for studies until March 23, 2021. We included studies if the enrolled patients were randomly allocated to a treatment or control group within $72 \mathrm{~h}$ following a tick bite and had no clinical evidence of Lyme disease at enrolment. The Preferred Reporting Items for Systematic Reviews and Meta-analyses (PRISMA) reporting guidelines were followed for data abstraction. Two authors (GZZ and $X X)$ independently reviewed the abstracts and identified articles for detailed assessment. We used a random-effects model to calculate the pooled results and reported the $95 \%$ confidence interval (Cl). Study quality was assessed using a modified Jadad scale, and publication bias was assessed using Egger's test. We calculated the risk ratio (RR) for the rates of unfavorable events in patients who received intervention versus the control group. This study is registered with PROSPERO, number CRD42021245002.
\end{abstract}

Results: Six studies (3,766 individuals) were included. The pooled rate of unfavorable events in persons receiving treatment and the control group were $0.4 \%$ (95\%Cl: $0.1-1.1 \%)$ and $2.2 \%(95 \% \mathrm{Cl}: 1.6-3.0 \%)$, respectively. The pooled RR was 0.38 (95\%Cl: 0.22-0.66). Subgroup analysis revealed that the pooled RR was 0.29 (95\%Cl: $0.14-0.60)$ in the singleuse 200-mg doxycycline group; 0.28 (95\%Cl: 0.05-1.67) in a 10-day course group (Amoxicillin, Penicillin or tetracycline); and 0.73 (95\%Cl: 0.25-2.08) in a topical antibiotic treatment group (Azithromycin).

Conclusions: The available evidence supports the use of antibiotics for the prevention of Lyme disease, and reveals advantages of using single-dose; however, further confirmation is needed.

Keywords: Borrelia burgdorferi, Borreliosis, Ixodes, Lyme disease, Tick bite

*Correspondence: liuaihua@kmmu.edu.cn; baofukai@kmmu.edu.cn

${ }^{1}$ The Institute for Tropical Medicine, School of Basic Medical Sciences,

Kunming Medical University, Kunming 650500, China

Full list of author information is available at the end of the article

\section{Introduction}

Lyme disease is the most common tick-borne disease in the northern hemisphere and is caused by the spirochetes Borrelia burgdorferi (B. burgdorferi) [1]. The United States has an estimated 300,000 cases of Lyme disease annually [2], and 65,500-85,000 cases are reported 
annually in Europe [3]. Early manifestations of Lyme disease include non-specific signs and symptoms such as fever, headache, and myalgias. Within days or weeks, untreated infection can spread to other parts of the body, causing more serious neurologic conditions (e.g., meningitis, radiculopathy, and facial palsy) or cardiac abnormalities (e.g., carditis with atrioventricular heart block). Over a period of months or years, untreated infection can lead to arthritis, peripheral neuropathy, or encephalopathy $[4,5]$.

In areas where Lyme disease is endemic, bites from ticks are common. For instance, $25-30 \%$ of people from endemic areas in the United States have reported that a member of the household was bitten by a tick in the preceding year [6]. However, no vaccine for humans is yet available against Lyme disease $[7,8]$. Therefore, the feasibility of using antibiotic prophylaxis to prevent Lyme disease following a tick bite is worth further investigation. However, in the past three decades, there have been some controversies over antibiotic prophylaxis to prevent Lyme disease following a tick bite [9-13], and the recommendations of guidelines were conflicting [14]. In 2006 [15], guidelines from the Infectious Diseases Society of America (IDSA) stated that a single dose of $200 \mathrm{mg}$ doxycycline may be offered to adult patients. In 2014 [16], guidelines from the International Lyme and Associated Diseases Society (ILADS) recommended prompt prophylaxis with doxycycline $100-200 \mathrm{mg}$ twice daily for a minimum of 20 days for all Ixodes tick bites to the persons who carried evidence of tick feeding, regardless of the degree of tick engorgement or the infection rate in the local tick population. In 2019, guidelines from French Scientific Societies stated that initiating an antibiotic therapy is not recommended, irrespective of the patient's age, duration of tick attachment, and the stage of development of the extracted tick [7]. In 2020, guidelines from IDSA, American Academy of Neurology (AAN), and American College of Rheumatology (ACR) recommended the administration of a single dose of oral doxycycline within $72 \mathrm{~h}$ of tick removal and observation in all age groups [17].

In 1996, Warshafsky et al. published a meta-analysis including three studies and found that the efficacy of antibiotic prophylaxis for prevention of Lyme disease was uncertain, as the $95 \%$ confidence interval $(\mathrm{CI})$ was wide [18]. In 2010, Warshafsky et al. updated the metaanalysis, which added one new study into the statistical analysis, and reported that antibiotic prophylaxis was effective for prevention of Lyme disease following a tick bite [19]. However, only 1,082 subjects were included and unfavorable events were scarce in the meta-analysis. Moreover, the efficacy of different treatment strategies could not be assessed. To address these inconsistencies, we performed this updated meta-analysis and explored more precise evidence for an in-depth assessment of the efficacy of antibiotic prophylaxis for prevention of Lyme disease, and attempted to identify the preferred treatment strategy.

\section{Methods}

\section{Search strategy}

We adhered to the PRISMA guidelines for conducting the present meta-analysis, and it was registered in PROSPERO (CRD42021245002). We identified eligible studies by searching PubMed, EMBASE, and the Cochrane Library. We collected studies from the earliest available date, i.e., January 1, 1962 to March 23, 2021. As mentioned in Warshafsky et al. study [19], the following keyword combinations were used: "(Lyme or borreliosis) and (prophylaxis or prevention)," without language restrictions. To minimize publication bias, we retrieved the reference lists of included studies and manually searched for other relevant studies that met our inclusion criteria.

\section{Selection criteria}

All studies in which the enrolled patients were randomly allocated to a treatment or control group, were enrolled within $72 \mathrm{~h}$ following an Ixodes tick bite, and had no clinical evidence of Lyme disease at enrolment were included in our analysis. There were no restrictions based on the antibiotics used, age of the enrolled patients, length of patient follow-up, or the observed outcomes. All included studies were assessed independently by two authors (GZZ and XX). Disagreement for a particular assessment was resolved by discussing the issues with the third partner until a consensus was reached.

\section{Data extraction}

The two authors (GZZ and XX) independently reviewed the abstracts and identified articles for detailed assessment. Disagreement for a particular assessment was resolved by discussing the issues until a consensus was reached. The form included a fixed set of fields: title, author, years of publication, country or area, patient demographics, antibiotics used, daily dose of antibiotics, duration of therapy, duration of follow-up, number of patients in the antibiotic-treatment group and control group, and the number of unfavorable events in each study group. As mentioned in Warshafsky et al. study [19], an unfavorable event was defined as the development of erythema migrans at the site of the tick bite or an objective manifestation compatible with early extracutaneous Lyme disease (e.g., seventh cranial nerve palsy) or late Lyme disease (e.g., arthritis) confirmed by seroconversion. 


\section{Quality assessment}

We appraised the quality of studies by using a modified Jadad Scale, which included four parts: randomization, with scores ranging from 0 to 2 ; concealment of allocation,with scores ranging from 0 to 2; double blinding, with scores ranging from 0 to 2; withdrawals and dropouts, with scores ranging from 0 to 1 . Studies with a Jadad score between 1 and 3 were considered low quality, while those with a score between 4 and 7 were considered high quality. The quality of all studies was assessed independently by the same two authors (GZZ and XX). As mentioned, any disagreement was resolved by detailed discussion until consensus was achieved.

\section{Statistical analysis}

We calculated the risk ratio (RR) for the rates of unfavorable events in patients who received intervention versus the control group. Results from studies were grouped according to the treatment strategy of antibiotics, and we also conducted a sensitivity analysis to assess the robustness of results. We used Cochran's Q test and Higgins $\mathrm{I}^{2}$ statistic to assess the heterogeneity of the included studies. We used a random-effects model to calculate the pooled results and the $95 \% \mathrm{CI}$. A $p$-value $<0.10$ or a $\mathrm{I}^{2}$ value $>50 \%$ suggested significant heterogeneity. Egger's test was used to detect publication bias, and a $p$-value $<0.10$ on Egger's test was considered indicative of statistically significant publication bias. This meta-analysis was conducted using the "meta" package in $\mathrm{R}$ statistical software version 3.4.3 (Schwarzer, 2007; Team, 2017).

\section{Results}

Initially, 4,515 studies were identified and 4,509 were excluded after screening the titles and abstracts, as well as the full texts of all articles according to the inclusion criteria.

Six randomized controlled trials (RCTs) [3, 9, 20-23] met the inclusion and exclusion criteria and were eligible for the final analysis. The selection process is shown in Fig. 1. The characteristics of the included studies are shown in Table 1, and the quality assessment performed by Jadad Scale is shown in Table 2.

A total of 3,766 human participants were included in our meta-analysis, and 56 unfavorable events were observed. Of the 56 unfavorable events, 55 were erythema migrans, and only one was disseminated Lyme disease. Meta-analysis showed that the pooled rates of unfavorable events in patients who received intervention and control groups were $0.4 \%$ (95\%CI: $0.1-1.1 \%, \mathrm{I}^{2}=55 \%$ ) and $2.2 \%\left(95 \% \mathrm{CI}: 1.6-3.0 \%, \mathrm{I}^{2}=5 \%\right)$, respectively. The pooled RR was 0.38 (95\%CI: $0.22-0.66, \mathrm{I}^{2}=0 \%$ ) (Table 3 and Fig. 2).

Oral antibiotic therapy was administered in five studies, and the pooled rate of unfavorable events in patients who received intervention and control groups were $0.2 \%$ (95\%CI: $\left.0.0-1.0 \%, \mathrm{I}^{2}=57 \%\right)$ and $2.5 \%$ (95\%CI: $1.7-3.5 \%$, $\left.\mathrm{I}^{2}=0 \%\right)$, respectively. The pooled RR was $0.29(95 \% \mathrm{CI}$ : $0.15-0.57, \mathrm{I}^{2}=0 \%$ ) (Table 3 ). Of these five studies, a 10-day course of antibiotic treatment was administered in three studies, and the pooled rate of unfavorable events in patients who received intervention and control groups were $0.0 \%$ (95\%CI: $\left.0.0-0.3 \%, \mathrm{I}^{2}=0 \%\right)$ and $1.3 \%$ (95\%CI: $0.3-2.9 \%, \mathrm{I}^{2}=0 \%$ ), respectively. The pooled RR was 0.28 (95\%CI: $0.05-1.67, \mathrm{I}^{2}=0 \%$ ). A single-dose 200 $\mathrm{mg}$ doxycycline therapy was administered in the remaining two studies, and the pooled rates of unfavorable events in persons with intervention and control groups were $0.8 \%$ (95\%CI: $\left.0.4-1.4 \%, \mathrm{I}^{2}=0 \%\right)$ and $3.0 \%$ (95\%CI: $\left.2.0-4.2 \%, \mathrm{I}^{2}=0 \%\right)$, respectively. The pooled RR was 0.29 (95\%CI: $0.14-0.60, \mathrm{I}^{2}=0 \%$ ). Topical antibiotic treatment was administered in only one study, and the pooled rates of unfavorable events in patients who received intervention and control groups were $1.2 \%$ (95\%CI: $0.4-2.3 \%$ ) and 1.6\% (95\%CI: $0.7-2.9 \%)$, respectively. The RR was 0.73 (95\%CI: 0.25-2.08) (Table 3 and Fig. 2).

The results of sensitivity analysis showed that the confidence interval of the pooled RR became imprecise when Harm et al's study [9] was excluded (Fig. 3). Egger's test was used to assess for any publication bias among the six studies, and no evidence of publication bias was found in this review $(p=0.515)$.

\section{Discussion}

Our study included more participants than a previous meta-analysis [19] (3,766 vs. 1,082), and strengthened the evidence that prophylactic antibiotic use is effective for the prevention of Lyme disease following a tick bite. Furthermore, our subgroup analysis revealed that patients who received a single dose $(200 \mathrm{mg}$ ) course were shown to be less likely to develop Lyme disease than those given placebo (RR, 0.29 [95\%CI: 0.14-0.60]), but there is no evidence of the effectiveness of a 10-day course and topical antibiotics course (RR, 0.28 [95\%CI: 0.05-1.67] and 0.73 [95\%CI: $0.25-2.08$ ]), respectively. Our results support the strategy of a single-dose oral doxycycline therapy for prevention of Lyme disease.

As early as 2001, Nadelman et al. assessed the effect of doxycycline in the prevention of Lyme disease. However, the effectiveness estimated in the RCTs showed a wide confidence interval $(\mathrm{RR}=0.13$ [0.02-1.04]) [23]. Until recently, an RCT [9] with a relatively large sample size $(n=1,089)$ provided stronger evidence that a single dose of doxycycline can prevent the development 


\section{6 records identified by database search}

5 records identified by other sources

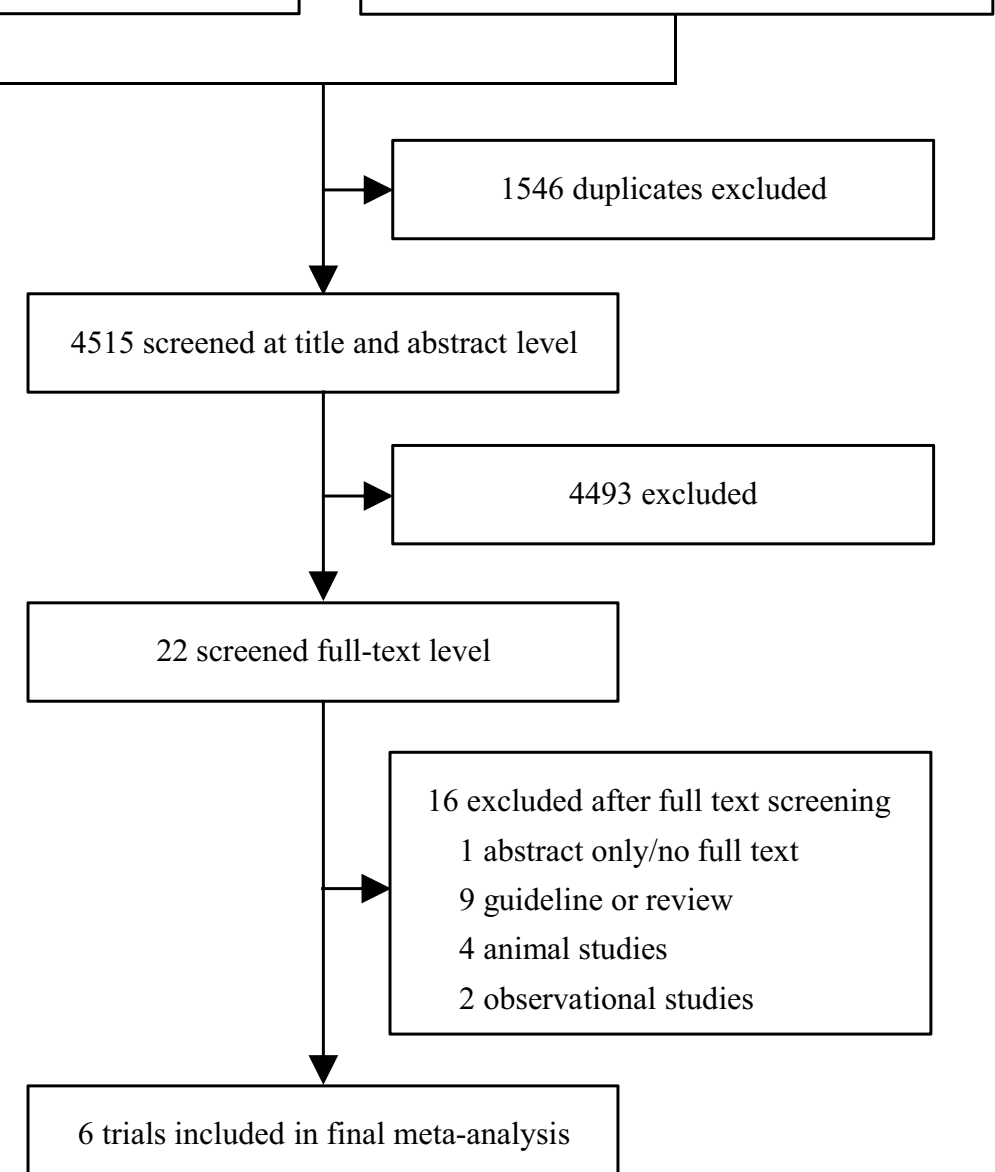

Fig. 1 Preferred Reporting Items for Systematic Reviews and Meta-analyses (PRISMA) flowchart of study selection process

Table 1 Characteristics of randomized clinical trials included in meta-analysis

\begin{tabular}{|c|c|c|c|c|c|c|c|c|}
\hline & Area & Age & Males (\%) & Antibiotic & Oral or topical & $\begin{array}{l}\text { Daily dose } \\
\text { (mg) }\end{array}$ & Duration (d) & Follow-up (m) \\
\hline $\begin{array}{l}\text { Costello et al. } \\
1989[20]\end{array}$ & USA & $\begin{array}{l}\text { Adults and } \\
\text { children }\end{array}$ & 35.7 & Penicillin & Oral & 1000 & 10 & \\
\hline $\begin{array}{l}\text { Shapiro et al. } \\
1992 \text { [21] }\end{array}$ & USA & $\begin{array}{l}\text { Adults and } \\
\text { children }\end{array}$ & 42.6 & Amoxicillin & Oral & 750 & 10 & $12^{b}$ \\
\hline $\begin{array}{l}\text { Agre et al. } 1993 \\
\text { [22] }\end{array}$ & USA & Children & 49.2 & $\begin{array}{l}\text { Penicillin or } \\
\text { tetracycline }\end{array}$ & Oral & 1000 & 10 & $12-36$ \\
\hline $\begin{array}{l}\text { Nadelman et al. } \\
2001 \text { [23] }\end{array}$ & USA & $\begin{array}{l}\text { Adults and } \\
\text { children }\end{array}$ & 53.3 & Doxycycline & Oral & 200 & 1 & 1.5 \\
\hline $\begin{array}{l}\text { Schwameis et al. } \\
2016 \text { [3] }\end{array}$ & $\begin{array}{l}\text { Germany and } \\
\text { Austria }\end{array}$ & Adults & 48.7 & Azithromyci & Topical & - & 3 & 2 \\
\hline $\begin{array}{l}\text { Harms et al. } \\
2021 \text { [9] }\end{array}$ & Netherlands & $\begin{array}{l}\text { Adults and } \\
\text { children }\end{array}$ & 50.0 & Doxycycline & Oral & 200 & 1 & 6 \\
\hline
\end{tabular}

${ }^{a}$ Patients older than 9 years received tetracycline and those younger than 9 years received penicillin

${ }^{b}$ Visit follow-up for 3 months, and telephone follow-up for 12 months 
Table 2 Quality assessment performed by Jadad Scale of included studies

\begin{tabular}{|c|c|c|c|c|c|c|}
\hline & $\begin{array}{l}\text { Costello et al. } \\
1989 \text { [20] }\end{array}$ & $\begin{array}{l}\text { Shapiro et al. } \\
1992 \text { [21] }\end{array}$ & $\begin{array}{l}\text { Agre et al. } 1993 \\
\text { [22] }\end{array}$ & $\begin{array}{l}\text { Nadelman et al. } \\
2001 \text { [23] }\end{array}$ & $\begin{array}{l}\text { Schwameis et al. } \\
2016 \text { [3] }\end{array}$ & $\begin{array}{l}\text { Harms } \\
\text { et al. } 2021 \\
\text { [9] }\end{array}$ \\
\hline Randomization & 1 & 2 & 2 & 2 & 2 & 2 \\
\hline Concealment of allocation & 2 & 2 & 2 & 2 & 2 & $0^{a}$ \\
\hline Double blinding & 2 & 2 & 2 & 2 & 2 & $0^{\mathrm{a}}$ \\
\hline Withdrawals and dropouts & 1 & 1 & 1 & 0 & 1 & 1 \\
\hline Total Jadad quality score & 6 & 7 & 7 & 6 & 7 & 3 \\
\hline
\end{tabular}

a Controls did not receive any treatment including placebo, so concealment of allocation and double blinding could not be achieved

Table 3 Main outcomes measures, for total calculation and subgroups

\begin{tabular}{llllllllll}
\hline & Studies (n) & Participants $(\mathbf{n})$ & $\begin{array}{l}\text { Rate in } \\
\text { intervention } \\
(\%)\end{array}$ & $\mathbf{I}^{\mathbf{2}}(\%)$ & Participants $(\mathbf{n})$ & Rate in control (\%) & $\mathbf{I}^{\mathbf{2}}(\%)$ & Risk ratio & $\mathbf{I}^{\mathbf{2}}(\%)$ \\
\hline Oral treatment & 5 & 1584 & $0.2(0.0-1.0)$ & 57 & 1187 & $2.5(1.7-3.5)$ & 0 & $0.29(0.15-0.57)$ & 0 \\
10-day course & 3 & 308 & $0.0(0.0-0.3)$ & 0 & 292 & $1.3(0.3-2.9)$ & 0 & $0.28(0.05-1.67)$ & 0 \\
Single dose & 2 & 1276 & $0.8(0.4-1.4)$ & 0 & 895 & $3.0(2.0-4.2)$ & 0 & $0.29(0.14-0.60)$ & 0 \\
Topical treatment & 1 & 505 & $1.2(0.4-2.3)$ & N/A & 490 & $1.6(0.7-2.9)$ & N/A & $0.73(0.25-2.08)$ & N/A \\
Total & 6 & 2089 & $0.4(0.1-1.1)$ & 55 & 1677 & $2.2(1.6-3.0)$ & 5 & $0.38(0.22-0.66)$ & 0 \\
\hline
\end{tabular}

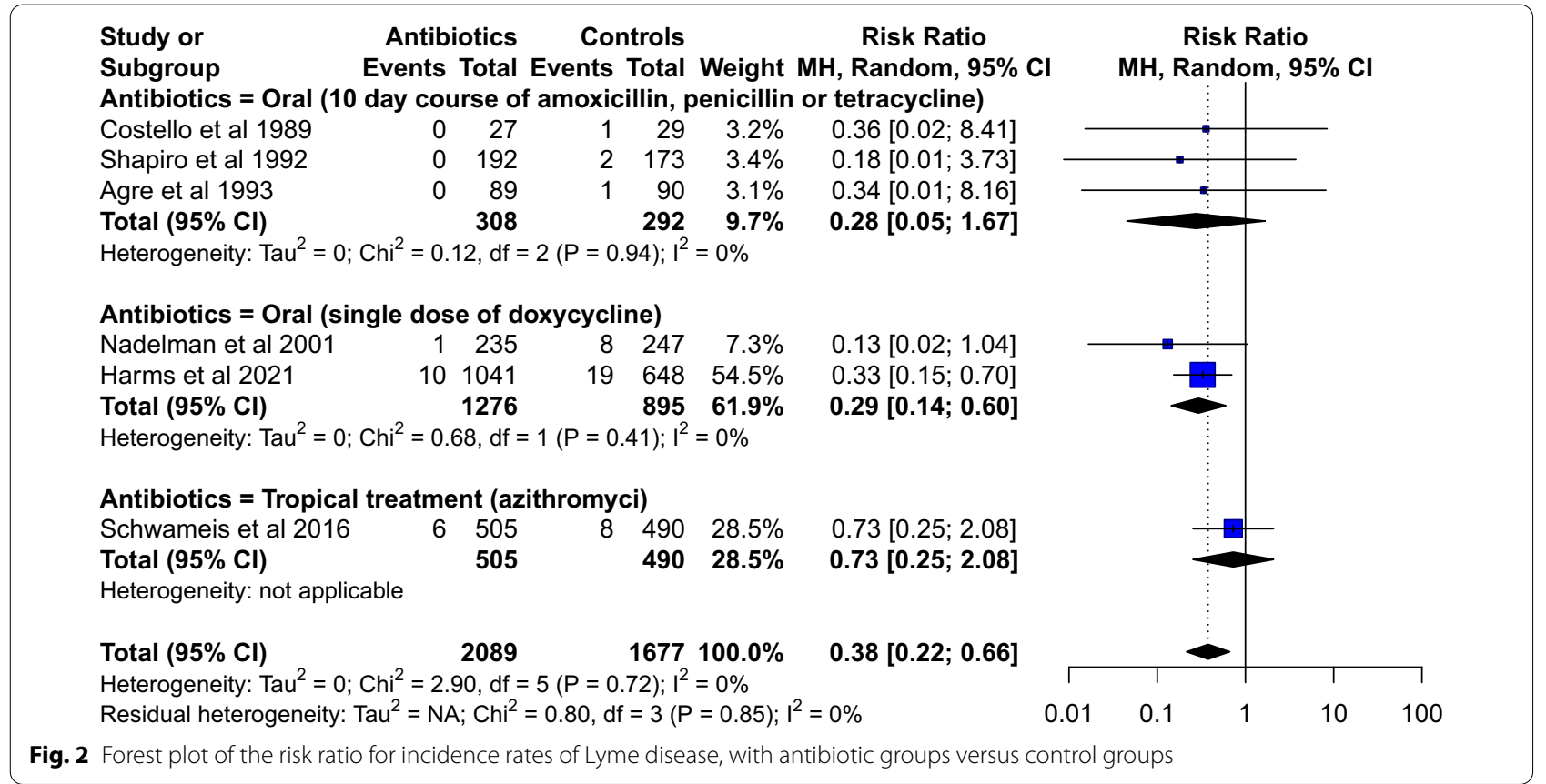

of Lyme disease, following a bite from Ixodes ricinus $(\mathrm{RR}=0.33$ [0.15-0.70]). Our meta-analysis combined two RCTs and showed a more accurate CI $(R R=0.29$ (0.14-0.60]). Additionally, two observational studies reported the results of doxycycline in the prevention of Lyme disease. Korenberg et al. [24] reported that none of the patients in the experimental group $(n=261)$ developed erythema migrans after receiving doxycycline (100 mg twice daily) for 3-5 days after the tick bite, whereas 5/97 patients developed erythema migrans in the control group which did not receive any antibiotics. Jackson et al. [25] reported the clinical 


\section{Study \\ Omitting Costello et al 1989 \\ Omitting Shapiro et al 1992 \\ Omitting Agre et al 1993 \\ Omitting Nadelman et al 2001 \\ Omitting Schwameis et al 2016 \\ Omitting Harms et al 2021}

Total $(95 \% \mathrm{Cl})$

Risk Ratio
MH, Random, 95\% C
$0.38[0.21 ; 0.67]$
$0.39[0.22 ; 0.69]$
$0.38[0.21 ; 0.67]$
$0.41[0.23 ; 0.74]$
$0.29[0.15 ; 0.57]$
$0.45[0.20 ; 1.03]$
$\mathbf{0 . 3 8}[\mathbf{0 . 2 2} ; \mathbf{0 . 6 6}]$

Risk Ratio

$0.38[0.21 ; 0.67]$

$0.39[0.22 ; 0.69]$

$0.38[0.21 ; 0.67]$

$0.41[0.23 ; 0.74]$

$0.29[0.15 ; 0.57]$

$0.38[0.22 ; 0.66]$

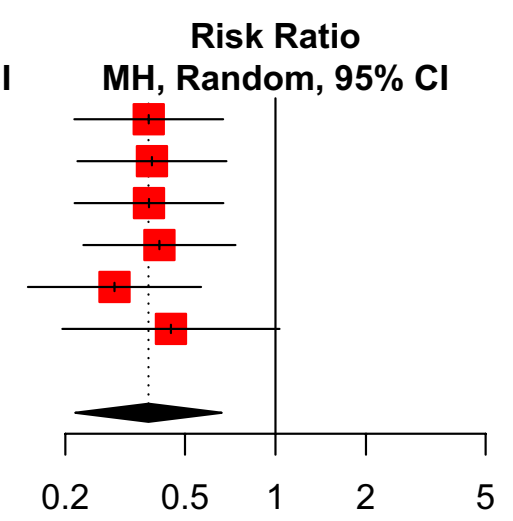

Fig. 3 The sensitivity analysis of the six included studies

application of doxycycline for Lyme disease prophylaxis, and the results indicated a high level of satisfaction with the pharmacy services provided, with no reports of subsequent development of Lyme disease symptoms or other side effects. However, the sample size of this study was small $(n=8)$.

Although our results support the use of antibiotics for the prevention of Lyme disease and the advantages of a single dose of doxycycline, routine use of antibiotic prophylaxis is not recommended after a recognized tick bite [17]. In our meta-analysis, we estimated that 50 patients (95\%CI: $25-100)$ would need to be treated (NNT) with single-dose doxycycline to prevent one case of Lyme disease. Therefore, it is essential to determine who is at high risk of infection and who is worthy of treatment. For instance, animal studies have shown an exponential increase in the risk of $B$. burgdorferi infection after 48-72 h of deer tick attachment [26, 27]. Consequently, guidelines state that a tick bite is considered to be high-risk only if it was attached for more than $36 \mathrm{~h}$ [16]. Falco et al. reported that $52.5 \%$ of all tick bites had been attached for $<36 \mathrm{~h}$ [28], so the recommendation represents that nearly half of patients avoid receive antibiotics treatment. Additionally, Nadelman et al. [23] found that ticks which were partially engorged with blood (with incidence rate of 9.9\%), rather than unfed ticks (incidence rate of $0 \%$ ), were associated with the development of erythema migrans. Nadelman et al. [23] found that erythema migrans developed more frequently after bites from nymphal ticks than after bites from adult ticks, with an incidence rate of $5.6 \%$ and $0 \%$, respectively. Harms et al. [9] revealed that $11.1 \%$ untreated patients with a $B$. burgdorferi-positive tick bite developed Lyme disease, and the NNT in this subgroup was only 10 . These findings might provide valuable information for clinicians, but need further confirmation.
Antibiotic use has some side effects [13]. The major side effects of oral doxycycline include enterocolitis, anaphylaxis (including angioedema), Stevens-Johnson syndrome, severe urticarial reactions, and a lupus-like syndrome. Minor reactions of intravenous ceftriaxone include gastrointestinal symptoms of abdominal pain, nausea, vomiting, and diarrhea, and hypersensitivity reactions such as rash, pruritus, fever and chills, candidiasis, and local reactions at the injection site [14]. Although none of included studies reported serious side effects, there were still many minor side effects reported such as rash or nausea. The two studies revealed that incidence of mild side effects after using single-dose doxycycline was $5.9-30.1 \%[9,23]$, which suggests that up to a third of patients are likely to suffer mild side effects. Furthermore, Nadelman et al. found that $18.2 \%$ of patients were recognized additional tick bites after enrollment, but during the 6-week study period, the participants needed repeated antibiotic prophylaxis, which would strongly increased the risk of side effects [23]. Availability of a universally acceptable and effective prophylactic agent with minimal side effects would be the ideal. Previous studies found that topical azithromycin was highly effective when applied topically at the sites of tick bites in mice $[29,30]$. Although no effective evidences were found in human trials [3], a topical pharmacological prophylactic strategy is still worth exploring [31], given that minor side effects such as localized itching, redness, and dryness were reported only in $1.6 \%$ patients [3].

Our meta-analysis has some limitations. First, although we screened more than 4000 related articles, only six studies were eligible for final analysis. Second, we included 4 studies from USA and 2 studies from Europe, the difference of Ixodes species and B. burgdorferi subspecies between the USA and Europe may bring heterogeneity. Third, erythema migrans was considered 
as the main end point of all included studies evaluating antibiotic prophylaxis, since it is the most common clinical manifestation and only reliable marker of infection caused by $B$. burgdorferi infection. However, this end point was limited and could have resulted in underestimation of the actual incidence of $B$. burgdorferi infection. Fourth, Harm et al. study [9], which included 1689 participants, contributed $54.5 \%$ of the weight to the pooled results, but this study was the only one assessed as low quality (Jadad score 3 ). Therefore, our evidence is limited and further confirmation is needed. Last, we did not analyze the seroconversion results, because only few patients showed seroconversion even in the control group.

\section{Conclusion}

The available evidence supports the prophylactic use of antibiotics for the prevention of Lyme disease and the advantages of a single dose of doxycycline, but further confirmation is needed.

\section{Abbreviations}

B. Burgdorferi: Borrelia burgdorferi; Cl: Confidence interval; RR: Risk ratio; RCTs: Randomized controlled trials; NNT: Need to be treated.

\section{Acknowledgements}

Not applicable.

\section{Authors' contributions}

GZZ, FKB and AHL conceived the study and had full access to all of the data in the study and take responsibility for the integrity of the data and the accuracy of the data analysis. GZZ and XX did the literature search, selected the studies, extracted the relevant information and synthesized the data. YZ, YP and SQL developed the protocol. GZZ completed the analysis and maintained the database. GZZ, FKB and AHL wrote the first draft of the paper and all authors critically revised successive drafts of the paper and approved its final version. All authors read and approved the final manuscript.

\section{Funding}

This work was supported by National Natural Science Foundation of China Grants 31560051, 81560596, and 81860644, and Natural Foundation of Yunnan Province Grants 2019FE001-(002) and 2017FE467-(001). The funding organizations had no role in the design and conduct of the study; collection, management, analysis, and interpretation of the data; preparation, review, or approval of the manuscript; and decision to submit the manuscript for publication.

\section{Availability of data and materials}

The datasets used and/or analyzed during the current study are available from the corresponding author on reasonable request.

\section{Declarations}

Ethics approval and consent to participate Not required.

\section{Consent for publication}

Not required.

\section{Competing interests}

None of the authors in this study have any conflict of interest regarding the publication of the paper.

\section{Author details}

${ }^{1}$ The Institute for Tropical Medicine, School of Basic Medical Sciences, Kunming Medical University, Kunming 650500, China. ${ }^{2}$ Yunnan Province Key Laboratory for Tropical Infectious Diseases in Universities, Kunming Medical University, Kunming 650500, China.

Received: 26 May 2021 Accepted: 22 October 2021

Published online: 08 November 2021

\section{References}

1. Steere AC, Strle F, Wormser GP, et al. Lyme borreliosis. Nat Rev Dis Primers. 2016;2:16090. https://doi.org/10.1038/nrdp.2016.90.

2. Nelson CA, Saha S, Kugeler KJ, et al. Incidence of Clinician-Diagnosed Lyme Disease, United States, 2005-2010. Emerg Infect Dis. 2015;21(9):1625-31. https://doi.org/10.3201/eid2109.150417.

3. Schwameis M, Kündig T, Huber G, et al. Topical azithromycin for the prevention of Lyme borreliosis: a randomised, placebo-controlled, phase 3 efficacy trial. Lancet Infect Dis. 2017;17(3):322-9. https://doi.org/10.1016/ S1473-3099(16)30529-1.

4. Bacon RM, Kugeler KJ, Mead PS. Surveillance for Lyme disease--United States, 1992-2006. MMWR Surveill Summ. 2008;57(10):1-9. https://www. cdc.gov/mmwr/preview/mmwrhtml/ss5710a1.htm

5. Schoen RT. Lyme disease: diagnosis and treatment. Curr Opin Rheumatol. 2020;32(3):247-54. https://doi.org/10.1097/BOR.0000000000000698.

6. Hook SA, Nelson CA, Mead PS. public's experience with ticks and tickborne diseases: Results from national Health Styles surveys. Ticks Tick Borne Dis. 2015;6(4):483-8. https://doi.org/10.1016/j.ttbdis.2015.03.017.

7. Figoni J, Chirouze C, Hansmann Y, et al. Lyme borreliosis and other tickborne diseases. Guidelines from the French Scientific Societies (I): prevention, epidemiology, diagnosis. Med Mal Infect. 2019;49(5):318-34. https:// doi.org/10.1016/j.medmal.2019.04.381.

8. Richardson M, Khouja C, Sutcliffe K. Interventions to prevent Lyme disease in humans: A systematic review. Prev Med Rep. 2019;13:16-22. https://doi.org/10.1016/j.pmedr.2018.11.004.

9. Harms MG, Hofhuis A, Sprong H, et al. A single dose of doxycycline after an ixodes ricinus tick bite to prevent Lyme borreliosis: An open-label randomized controlled trial. J Infect. 2021;82(1):98-104. https://doi.org/ 10.1016/j.jinf.2020.06.032.

10. Wormser GP, Warshafsky S, Visintainer P. Aggregation of data from 4 clinical studies demonstrating efficacy of single-dose doxycycline postexposure for prevention of the spirochetal infections: Lyme disease, syphilis, and tick-borne relapsing fever. Diagn Microbiol Infect Dis. 2021;99(4): 115293. https://doi.org/10.1016/j.diagmicrobio.2020.115293.

11. D'Alessandro M, Loy A, Castagnola E. Management of lyme disease in european children: a review for practical purpose. Curr Infect Dis Rep. 2017;19(8):27. https://doi.org/10.1007/s11908-017-0582-9.

12. Ogden NH, Lindsay LR, Schofield SW. Methods to prevent tick bites and lyme disease. Clin Lab Med. 2015;35(4):883-99. https://doi.org/10.1016/j. cll.2015.07.003.

13. Wormser GP. Doxycycline for prevention of spirochetal infections: status report. Clin Infect Dis. 2020;71(8):2014-7. https://doi.org/10.1093/cid/ ciaa240.

14. Sutton DSpry C. One Dose of Doxycycline for the Prevention of Lyme Disease: A Review of Clinical Effectiveness and Guidelines. Ottawa (ON): Canadian Agency for Drugs and Technologies in Health; 2019. https:// www.ncbi.nlm.nih.gov/books/NBK545493/

15. Wormser GP, Dattwyler RJ, Shapiro ED, et al. The clinical assessment, treatment, and prevention of lyme disease, human granulocytic anaplasmosis, and babesiosis: clinical practice guidelines by the Infectious Diseases Society of America. Clin Infect Dis. 2006;43(9):1089-134. https://doi.org/ 10.1086/508667.

16. Cameron DJ, Johnson LB, Maloney EL. Evidence assessments and guideline recommendations in Lyme disease: the clinical management of known tick bites, erythema migrans rashes and persistent disease. Expert Rev Anti Infect Ther. 2014;12(9):1103-35. https://doi.org/10.1586/14787 210.2014.940900.

17. Lantos PM, Rumbaugh J, Bockenstedt LK, et al. Clinical Practice Guidelines by the Infectious Diseases Society of America (IDSA), American Academy 
of Neurology (AAN), and American College of Rheumatology (ACR): 2020 Guidelines for the Prevention, Diagnosis and Treatment of Lyme Disease. Clin Infect Dis. 2021;72(1):1-8. https://doi.org/10.1093/cid/ciab049.

18. Warshafsky S, Nowakowski J, Nadelman RB, Kamer RS, Peterson SJ, Wormser GP. Efficacy of antibiotic prophylaxis for prevention of Lyme disease. J Gen Intern Med. 1996;1 1(6):329-33. https://doi.org/10.1007/BF02600042.

19. Warshafsky S, Lee DH, Francois LK, Nowakowski J, Nadelman RB, Wormser GP. Efficacy of antibiotic prophylaxis for the prevention of Lyme disease: an updated systematic review and meta-analysis. J Antimicrob Chemother. 2010;65(6):1137-44. https://doi.org/10.1093/jac/dkq097.

20. Costello CM, Steere AC, Pinkerton RE, Feder HM Jr. A prospective study of tick bites in an endemic area for Lyme disease. J Infect Dis. 1989;159(1):136-9. https://doi.org/10.1093/infdis/159.1.136.

21. Shapiro ED, Gerber MA, Holabird NB, et al. A controlled trial of antimicrobial prophylaxis for Lyme disease after deer-tick bites. N Engl J Med. 1992;327(25):1769-73. https://doi.org/10.1056/NEJM199212173272501.

22. Agre F, Schwartz R. The value of early treatment of deer tick bites for the prevention of Lyme disease. Am J Dis Child. 1993;147(9):945-7. https:// doi.org/10.1001/archpedi.1993.02160330035013.

23. Nadelman RB, Nowakowski J, Fish D, et al. Prophylaxis with single-dose doxycycline for the prevention of Lyme disease after an /xodes scapularis tick bite. N Engl J Med. 2001;345(2):79-84. https://doi.org/10.1056/NEJM2 00107123450201.

24. Korenberg El, Vorobyeva NN, Moskvitina HG, Lya G. Prevention of borreliosis in persons bitten by infected ticks. Infection. 1996;24(2):187-9. https://doi.org/10.1007/BF01713337.

25. Jackson AN, Orr KK, Bratberg JP, Silverblatt F. Pharmacist initiation of postexposure doxycycline for Lyme disease prophylaxis. J Am Pharm Assoc. 2014:54(1):69-73. https://doi.org/10.1331/JAPhA.2014.13106.
26. Piesman J. Dispersal of the Lyme disease spirochete Borrelia burgdorferi to salivary glands of feeding nymphal Ixodes scapularis (Acari: Ixodidae). J Med Entomol. 1995;32(4):519-21. https://doi.org/10.1093/jmedent/32.4. 519.

27. Piesman J. Dynamics of Borrelia burgdorferi transmission by nymphal Ixodes dammini ticks. J Infect Dis. 1993;167(5):1082-5. https://doi.org/10 1093/infdis/167.5.1082

28. Falco RC, Daniels TJ, Vinci V, McKenna D, Scavarda C, Wormser GP. Assessment of duration of tick feeding by the scutal index reduces need for antibiotic prophylaxis after Ixodes scapularis Tick Bites. Clin Infect Dis. 2018;67(4):614-6. https://doi.org/10.1093/cid/ciy221.

29. Knauer J, Krupka I, Fueldner C, Lehmann J, Straubinger RK. Evaluation of the preventive capacities of a topically applied azithromycin formulation against Lyme borreliosis in a murine model. J Antimicrob Chemother. 2011;66(12):2814-22. https://doi.org/10.1093/jac/dkr371.

30. Piesman J, Hojgaard A, Ullmann AJ, Dolan MC. Efficacy of an experimental azithromycin cream for prophylaxis of tick-transmitted lyme disease spirochete infection in a murine model. Antimicrob Agents Chemother. 2014;58(1):348-51. https://doi.org/10.1128/AAC.01932-13.

31. Jin N, Pyo SM, Keck CM, Müller RH. Azithromycin nanocrystals for dermal prevention of tick bite infections. Pharmazie. 2019;74(5):277-85. https:// doi.org/10.1691/ph.2019.8169.

\section{Publisher's Note}

Springer Nature remains neutral with regard to jurisdictional claims in published maps and institutional affiliations.
Ready to submit your research? Choose BMC and benefit from:

- fast, convenient online submission

- thorough peer review by experienced researchers in your field

- rapid publication on acceptance

- support for research data, including large and complex data types

- gold Open Access which fosters wider collaboration and increased citations

- maximum visibility for your research: over $100 \mathrm{M}$ website views per year

At BMC, research is always in progress.

Learn more biomedcentral.com/submissions 